\title{
Research on Evaluation of Classroom Teaching Based on the Distance of Vague Set
}

\author{
Chunlei Wan ${ }^{1}$, Hongxu Wang ${ }^{2}$, Chengyi Zhang ${ }^{3}$ \\ ${ }^{1}$ Zhumadian Secondary School, Zhumadian, Henan, China.463000 \\ ${ }^{2}$ Qiongzhou University, Sanya, Hainan, China, \\ ${ }^{3}$ Hainan Normal University, Haikou, Hainan, China, 571158,
}

Keywords: Vague sets; distance; optimal selection; teachers' classroom teaching

Abstract: A set of definitions and formulas about the distance between Vague value applications are given, and applied to the optimal selection sort method based on distance of Vague set, for the classroom teaching quality assessment and sort.

\section{Introduction}

Teaching quality is directly related to the student's education quality as well as the school's educational level. Currently the methods of teaching quality evaluation are mainly analytic hierarchy process (AHP) ${ }^{[1]}$, fuzzy analytic hierarchy process (FAHP) ${ }^{[2]}$, fuzzy comprehensive evaluation method $^{[3]}$, a fuzzy multiple index evaluation method of teaching quality based on Vague set ${ }^{[4]}$, the teacher evaluation analysis method based on improved TOPSIS ${ }^{[5]}$ and so on. Among which the methods given in literature [2] and [3] belong to the evaluation method of fuzzy set ${ }^{[6]}$. Methods given in literature [4] and [5] are the evaluation method of Vague set ${ }^{[7]}$. Different from the method [4] and [5] mentioned, this paper provides us an optimal sorting method based on distance of Vague set, which will be beneficial to the fair, accurate, scientific and objective evaluation of teachers' classroom teaching quality.

1. Distance between the Vague set (value)

Definition 1 the Vague value $x=\left[t_{x}, 1-f_{x}\right]$, then $t_{x}, f_{x}, \pi_{x}\left(=1-t_{x}-f_{x}\right), S_{x}\left(=t_{x}-f_{x}\right)$,

$K_{x}\left(=t_{x}+f_{x}\right)$ are called the sustaining degree, Vague value of the opposition, uncertainty and degree of certainty.

Theorem 1 if value set value is equal to $x=\left[t_{x}, 1-f_{x}\right], y=\left[t_{y}, 1-f_{y}\right]$. Then

$d(x, y)=\frac{\left|S_{x}-S_{y}\right|+\left|K_{x}-K_{y}\right|+\pi_{x}+\pi_{y}}{3}$.

(1) is the distance measure of Vague value $x$ and ${ }^{y}$.

Definition 2 If value set value is equal to $x=\left[t_{x}, 1-f_{x}\right], y=\left[t_{y}, 1-f_{y}\right]$, if the formula satisfies the following properties, it is called the distance measure of Vague value $x$ and $y$.

1). $0 \leq d(x, y) \leq 1$; 2). $d(x, y)=d(y, x)$; 3). If $z=\left[t_{z}, 1-f_{z}\right]$, then $d(x, z) \leq d(x, y)+d(y, z)$;

4). $d(x, y)=0$ if and only if $x=y, \pi_{x}=\pi_{y}=0$; 5). If $x=[0,0], y=[0,1]$ or $x=[0,1], y=[0,0]$

or $x=[1,1], y=[0,1]$ or $x=[0,1], y=[1,1]$, then $d(x, y)=1 ; 6) . x$ is closer to $y$ than $z$, if and only if $d(x, y) \leq d(z, y)$.

Similar to definition 2, we can define the distance and the weighted distance between Vague sets. No repeat here. Similar to Theorem 1, we can obtain the following formula for the distance and the weighted distance between Vague sets:

Theorem 2 Suppose the domain $U=\left\{u_{1}, u_{2}, \cdots, u_{n}\right\}$, the Vague set is in it, $X=\left(\left[t_{X}\left(u_{1}\right), 1-f_{X}\left(u_{1}\right)\right],\left[t_{X}\left(u_{2}\right), 1-f_{X}\left(u_{2}\right)\right], \cdots,\left[t_{X}\left(u_{n}\right), 1-f_{X}\left(u_{n}\right)\right]\right)$, 


$$
\begin{aligned}
& Y=\left(\left[t_{Y}\left(u_{1}\right), 1-f_{Y}\left(u_{1}\right)\right],\left[t_{Y}\left(u_{2}\right), 1-f_{Y}\left(u_{2}\right)\right], \cdots,\left[t_{Y}\left(u_{n}\right), 1-f_{Y}\left(u_{n}\right)\right]\right), \\
& \quad Z=\left(\left[t_{Z}\left(u_{1}\right), 1-f_{Z}\left(u_{1}\right)\right],\left[t_{Z}\left(u_{2}\right), 1-f_{Z}\left(x_{2}\right)\right], \cdots,\left[t_{Z}\left(u_{n}\right), 1-f_{Z}\left(u_{n}\right)\right]\right) . \\
& \text { respectively abbreviated as } X=\left(\left[t_{x 1}, 1-f_{x 1}\right], \cdots,\left[t_{x n}, 1-f_{x n}\right]\right), Y=\left(\left[t_{y 1}, 1-f_{y 1}\right], \cdots,\left[t_{y n}, 1-f_{y n}\right]\right), \\
& Z=\left(\left[t_{z 1}, 1-f_{z 1}\right], \cdots,\left[t_{z n}, 1-f_{z n}\right]\right) .
\end{aligned}
$$

Then the following formula $d(X, Y)$ is the distance between Vague set $X$ and $Y$ :

$$
d(X, Y)=\frac{1}{n} \sum_{i=1}^{n} \frac{\left|S_{x i}-S_{y i}\right|+\left|K_{x i}-K_{y i}\right|+\pi_{x i}+\pi_{y i}}{3} \text {. }
$$

Theorem 3 the following formula $W d(X, Y)$ is the weighted distance between Vague set $X$ and $Y$ : $W d(X, Y)=\sum_{i=1}^{n} \omega_{i} \cdot \frac{\left|S_{x i}-S_{y i}\right|+\left|K_{x i}-K_{y i}\right|+\pi_{x i}+\pi_{y i}}{3}$
$\quad \omega_{i}\left(0 \leq \omega_{i} \leq 1\right)$ 且 $\sum_{i=1}^{n} \omega_{i}=1$.

2 Distance-based Vague optimal selection sort

The optimal Vague set model $B$ and to be sorted model $A_{1}, A_{2}, \cdots, A_{m}$ are in the finite domain $X=\left\{x_{1}, x_{2}, \cdots, x_{n}\right\}$. We can apply the distance formula between Vague sets $d\left(A_{i}, B\right)(i=1,2, \cdots, m)$ to calculate the distance between Vague $A_{i}(i=1,2, \cdots, m)$ and $B$ $d\left(A_{i}, B\right)(i=1,2, \cdots, m)$. Then According to distance from small to large, the corresponding optimal selection model to be sorted sort.

3. Thinking about weights

Literature [5] adopts the use of information entropy method to determine the weight of evaluation index value and further to use the TOPSIS methods based on the Vague set for teacher evaluation. Literature [4] uses AHP method to determine the weight value of evaluation, which is calculated by a certain pattern, and finally get evaluation index weight vector. Advantages and disadvantages of this method are similar to the information entropy method to determine the value of evaluation index weights.

Views on the determination of the value of evaluation index weights

The common advantage is it can eliminate people's preferences and calculate weight values objectively when we use the information entropy weight method, analytic hierarchy process (AHP) or other application of a mathematical model to determine the weight value of evaluation index. The common disadvantage is it can only give a weight vector to the same question. Whether it is appropriate for this problem requires specific analysis. It is suitable for these problems, such as body light weighting scheme optimization ${ }^{[9]}$, soft foundation treatment plan optimization model ${ }^{[10]}$, and the cone drum screen main transmission structure optimization evaluation things. The application of the above objective weighting method is suitable.

But the problem for the evaluation of certain populations, recruitment of teachers teaching preferred sort, preferably young teacher teaching Prix sort, classroom teaching preferred sort, etc, which involve evaluation of certain groups. Expert assessment method should be a better choice. As for teacher's evaluation, the specialists have the final say. It is the experts who have to give the different weights according to the same evaluation conditions on different problems. But due to the different research questions the weight should be taken varyingly.

4. Quantitative values of Vague language

When in the research of the problem, the value has language value appears, you will need to carry on Vague language value quantification. Then it can enter the Vague environment. In this problem, the language value only takes five, as shown in table 2. Of course, the selection of 
language value can also be adjusted. The corresponding Vague quantitative value can have more choices.

Table 1 Quantitative values of Vague language

\begin{tabular}{|cccccc|}
\hline $\begin{array}{c}\text { Language value } \\
\text { poor }\end{array}$ & excellent & good & medium & fair \\
\hline $\begin{array}{c}\text { Vague } \\
{[0.4,0.5]}\end{array}$ & quantification & {$[0.9,1]$} & {$[0.7,0.9]$} & {$[0.6,0.7]$} & {$[0.5,0.6]$} \\
\hline
\end{tabular}

5. Evaluation method of primary and secondary school teacher's recruitment of teachers teaching Vague set

This is a design of" Vague sets evaluation method about the recruitment of the primary and secondary school teachers”.

5.1. Evaluation index of teaching quality

It adopts the evaluation index system of literature [4]. Selected evaluation is shown in Table 3.

Table2 Teachers' classroom teaching quality evaluation index

\begin{tabular}{|c|c|}
\hline Index level 1 & index level 2 \\
\hline \multicolumn{2}{|c|}{$\begin{array}{l}\mathrm{u}_{11} \text { Teaching syllabus, teaching calendar format, lesson plans, teaching progress, teaching document } \\
\text { are ready; }\end{array}$} \\
\hline Teaching attitude & $\begin{array}{l}\mathrm{u}_{12} \text { Detailed lesson plans, rigorous teaching, demanding teaching } \\
\mathrm{u}_{13} \text { Master student attendance, no teaching Accident }\end{array}$ \\
\hline & $\begin{array}{l}\mathrm{u}_{21} \text { scientific and actuate explanation on the concept and theory; Skilled content; An } \\
\text { emphasis on Difficult problems }\end{array}$ \\
\hline Teaching content & $\begin{array}{l}\mathrm{u}_{22} \text { Focus on linking theory with practice; unity of the basic and advanced knowledge } \\
\mathrm{u}_{23} \text { Conducive to the cultivation of students' innovative ability and inspiration }\end{array}$ \\
\hline Teaching methods & $\begin{array}{l}\mathrm{u}_{31} \text { Class structure is compact and reasonable, appropriate teaching arrangement } \\
\mathrm{u}_{32} \text { Use scientific and appropriate teaching methods to stimulate students learning } \\
\text { initiative and enthusiasm } \\
\mathrm{u}_{33} \text { Pay attention to the use of modern means of teaching, improve teaching quality }\end{array}$ \\
\hline $\begin{array}{l}\text { Teaching } \\
\text { expression }\end{array}$ & $\begin{array}{l}\mathrm{u}_{41} \text { Language expression is clear, logical, body language is natural; } \\
\mathrm{u}_{42} \quad \text { Blackboard design is rational and logical; }\end{array}$ \\
\hline $\begin{array}{l}\text { Teaching } \\
\text { effects }\end{array}$ & $\begin{array}{l}1_{51} \text { classroom order is good and students are active in class; } \\
1_{52} \text { The interaction between teachers and students are active; students feel good; }\end{array}$ \\
\hline
\end{tabular}

5.2. Tables of teachers being evaluated

Tables of teachers being evaluated varies according to the specific matter, which can be more consistent with the actual situation. For example, the design tables of the "recruitment of teachers lecture" shown in Table 4. the evaluation experts simply tick $(\sqrt{ })$ in evaluation of teacher for each candidate, while listening to their lectures as shown in Table 4 according to their own views. Chart 4 gives the score of candidate $\mathrm{A}_{1}$. This kind of language value method to score is more realistic than giving the score directly. For instance, as to index $\mathrm{u}_{11}$, giving the score of 93 is less realistic then giving an excellent. Especially for index $\mathrm{u}_{12}$, expert judgment is intended to be between "good" and "medium". It is ok to give a score of 70, 71 or 69 . But it is tangled for experts to give the candidate an exact score. We insist that maybe it is more realistic to give "good medium". Chart 4 shows not only the various index of the being evaluated teachers but gives the language value of A1 rating.

Table3 Tables of Recruitment of teachers' lecture

\begin{tabular}{|c|c|c|c|c|c|c|}
\hline $\begin{array}{l}\text { The } \\
\text { recruitment } \\
\text { of teachers } \\
\text { in Teaching }\end{array}$ & Name & $\mathrm{A}_{1}$ & Course & $\begin{array}{r}\text { Math } \\
\text { Senior } 1\end{array}$ & Time & $6 / 11 / 2012$ \\
\hline & & excellent & good & medium & fair & poor \\
\hline \multirow{3}{*}{$\begin{array}{l}\text { Teaching } \\
\text { attitude }\end{array}$} & $\mathrm{u}_{11}$ & $\sqrt{ }$ & & & & \\
\hline & $\overline{u_{12}}$ & & $\sqrt{ }$ & $\sqrt{ }$ & & \\
\hline & $\mathrm{u}_{13}$ & $\sqrt{ }$ & & & & \\
\hline \multirow{3}{*}{$\begin{array}{l}\text { Teaching } \\
\text { content }\end{array}$} & $\mathrm{u}_{21}$ & & $\sqrt{ }$ & $\sqrt{ }$ & & \\
\hline & $\mathrm{u}_{22}$ & & & & $\sqrt{ }$ & $\sqrt{ }$ \\
\hline & $\mathrm{u}_{23}$ & & & & $\sqrt{ }$ & \\
\hline
\end{tabular}




\begin{tabular}{|c|c|c|c|c|c|c|}
\hline \multirow{2}{*}{$\begin{array}{c}\text { Teaching } \\
\text { methods }\end{array}$} & $\mathrm{u}_{31}$ & & & $\checkmark$ & & \\
\hline & $\mathrm{u}_{32}$ & $\sqrt{ }$ & & & & \\
\hline & $\mathrm{u}_{33}$ & $\sqrt{ }$ & & & & \\
\hline \multirow{2}{*}{$\begin{array}{c}\text { Teaching } \\
\text { expression }\end{array}$} & $\mathrm{u}_{41}$ & & $\sqrt{ }$ & & & \\
\hline \multirow{2}{*}{$\begin{array}{c}\text { Teaching } \\
\text { effects }\end{array}$} & $\mathrm{u}_{42}$ & & & $\sqrt{ }$ & & \\
\hline & $\mathrm{u}_{51}$ & & & & & \\
\hline
\end{tabular}

5.3. The quantification of Vague language of the integral value table scores

Quantify the Vague language values of the obtained scores of teacher participants A1 by using the application in chart 2, whose result is listed in chart 5 . There are altogether 5 teachers taking part in the recruitment. The Vague language value scores of them have been quantified and listed in Table 5.

Table 4 Vague quantization table of the recruitment teachers' lecture

\begin{tabular}{|l|l|l|l|l|l|}
\hline & $\mathrm{A}_{1}$ & $\mathrm{~A}_{2}$ & $\mathrm{~A}_{3}$ & $\mathrm{~A}_{4}$ & $\mathrm{~A}_{5}$ \\
\hline $\mathrm{u}_{11}$ & {$[0.9,1]$} & {$[0.4,0.5]$} & {$[0.6,0.7]$} & {$[0.7,0.9]$} & {$[0.6,0.7]$} \\
\hline $\mathrm{u}_{12}$ & {$[0.6,0.9]$} & {$[0.7,0.9]$} & {$[0.6,0.9]$} & {$[0.6,0.9]$} & {$[0.7,1]$} \\
\hline $\mathrm{u}_{13}$ & {$[0.9,1]$} & {$[0.6,0.9]$} & {$[0.9,1]$} & {$[0.7,0.9]$} & {$[0.5,0.6]$} \\
\hline $\mathrm{u}_{21}$ & {$[0.7,0.9]$} & {$[0.9,1]$} & {$[0.7,0.9]$} & {$[0.5,0.6]$} & {$[0.6,0.7]$} \\
\hline $\mathrm{u}_{22}$ & {$[0.4,0.6]$} & {$[0.9,1]$} & {$[0.4,0.6]$} & {$[0.9,1]$} & {$[0.4,0.5]$} \\
\hline $\mathrm{u}_{23}$ & {$[0.5,0.6]$} & {$[0.5,0.6]$} & {$[0.5,0.6]$} & {$[0.6,0.7]$} & {$[0.5,0.7]$} \\
\hline $\mathrm{u}_{31}$ & {$[0.6,0.7]$} & {$[0.9,1]$} & {$[0.6,0.7]$} & {$[0.7,0.9]$} & {$[0.6,0.7]$} \\
\hline $\mathrm{u}_{32}$ & {$[0.9,1]$} & {$[0.6,0.7]$} & {$[0.9,1]$} & {$[0.7,1]$} & {$[0.9,1]$} \\
\hline $\mathrm{u}_{33}$ & {$[0.9,1]$} & {$[0.7,0.9]$} & {$[0.9,1]$} & {$[0.9,1]$} & {$[0.9,1]$} \\
\hline $\mathrm{u}_{41}$ & {$[0.7,0.9]$} & {$[0.6,0.7]$} & {$[0.7,0.9]$} & {$[0.6,0.7]$} & {$[0.7,0.9]$} \\
\hline $\mathrm{u}_{42}$ & {$[0.6,0.7]$} & {$[0.5,0.7]$} & {$[0.6,0.7]$} & {$[0.9,1]$} & {$[0.7,0.9]$} \\
\hline $\mathrm{u}_{51}$ & {$[0.5,0.6]$} & {$[0.6,0.9]$} & {$[0.5,0.6]$} & {$[0.7,1]$} & {$[0.7,0.9]$} \\
\hline $\mathrm{u}_{52}$ & {$[0.6,0.9]$} & {$[0.6,0.7]$} & {$[0.6,0.9]$} & {$[0.7,1]$} & {$[0.6,0.9]$} \\
\hline
\end{tabular}

5.4. Find the virtual Vague set points of the optimal teachers

Each candidate has been given the Vague set of teachers lecture scores in Table 5.According to the Vague set scores Virtual optimal teachers $B$, whose every index are the taken the optimal value among all the candidates. Because the Vague fraction is represented by a closed interval, the definition of "optimal values of each index" is in the five teachers teaching Vague set score, corresponding to the maximum Vague value of each index pointed in the

following formula.

$$
a_{i j}=\frac{1}{2}\left(t_{i j}+1-f_{i j}\right) \text {, }
$$

Calculation was carried out on the chart 5 . And we can get the result shown in table 6 . Thus the optimal virtual teacher $B$ of Vague sets is obtained scores as shown in table 6 .

Table5 Find the virtual Vague set points of the optimal teacher $B$

\begin{tabular}{|c|l|l|l|l|l|l|}
\hline & $\mathrm{A}_{1}$ & $\mathrm{~A}_{2}$ & $\mathrm{~A}_{3}$ & $\mathrm{~A}_{4}$ & $\mathrm{~A}_{5}$ & $\mathrm{~B}$ \\
\hline $\mathrm{u}_{11}$ & 0.95 & 0.45 & 0.65 & 0.80 & 0.65 & {$\left[\begin{array}{ll}0.9, & 1\end{array}\right]$} \\
\hline $\mathrm{u}_{12}$ & 0.75 & 0.80 & 0.75 & 0.75 & 0.85 & {$\left[\begin{array}{ll}0.7, & 1\end{array}\right]$} \\
\hline $\mathrm{u}_{13}$ & 0.95 & 0.75 & 0.95 & 0.80 & 0.55 & {$\left[\begin{array}{ll}0.9, & 1\end{array}\right]$} \\
\hline $\mathrm{u}_{21}$ & 0.80 & 0.95 & 0.80 & 0.55 & 0.65 & {$\left[\begin{array}{ll}0.9, & 1\end{array}\right]$} \\
\hline $\mathrm{u}_{22}$ & 0.50 & 0.95 & 0.50 & 0.95 & 0.45 & {$\left[\begin{array}{ll}0.9, & 1\end{array}\right]$} \\
\hline $\mathrm{u}_{23}$ & 0.55 & 0.55 & 0.55 & 0.65 & 0.60 & {$\left[\begin{array}{ll}0.6,0.7 \\
\hline\end{array}\right]$} \\
\hline $\mathrm{u}_{31}$ & 0.65 & 0.95 & 0.65 & 0.80 & 0.65 & {$\left[\begin{array}{ll}0.9, & 1\end{array}\right]$} \\
\hline $\mathrm{u}_{32}$ & 0.95 & 0.65 & 0.95 & 0.85 & 0.95 & {$\left[\begin{array}{ll}0.9, & 1\end{array}\right]$} \\
\hline $\mathrm{u}_{33}$ & 0.95 & 0.80 & 0.95 & 0.95 & 0.95 & {$\left[\begin{array}{ll}0.9, & 1\end{array}\right]$} \\
\hline $\mathrm{u}_{41}$ & 0.80 & 0.65 & 0.80 & 0.65 & 0.80 & {$\left[\begin{array}{ll}0.7,0.9\end{array}\right]$} \\
\hline $\mathrm{u}_{42}$ & 0.65 & 0.60 & 0.65 & 0.95 & 0.80 & {$\left[\begin{array}{ll}0.9, & 1\end{array}\right]$} \\
\hline $\mathrm{u}_{51}$ & 0.55 & 0.75 & 0.55 & 0.85 & 0.80 & {$\left[\begin{array}{ll}0.7, & 1\end{array}\right]$} \\
\hline $\mathrm{u}_{52}$ & 0.75 & 0.65 & 0.75 & 0.85 & 0.75 & {$\left[\begin{array}{ll}0.7, & 1\end{array}\right]$} \\
\hline
\end{tabular}


5.5. Teachers' queue based on Vague set distance

Application of the formula (2), we can calculate the virtual distance between each candidate and the best teachers and the calculation results are as follows:

$d\left(A_{1}, B\right)=0.205, d\left(A_{2}, B\right)=0.231, d\left(A_{3}, B\right)=0.238, d\left(A_{4}, B\right)=0.190, d\left(A_{5}, B\right)=0.223$.

Thus the sequence of the candidates are: $A_{4}, A_{1}, A_{5}, A_{2}, A_{3}$.if we recruit two teachers, ${ }^{A_{4}}$ and ${ }^{A_{1}}$ will be enrolled; if we need three teachers, ${ }^{A_{4}},{ }^{A_{1}}$ and ${ }^{A_{5}}$ will be enrolled.

\section{Acknowledgement}

This work is supported by NSF of China (71140008) and Hainan special social development technology (2011SFO3). Corresponding author: Chengyi Zhang.E-mail: chengyizh@hainnu.edu.cn.

\section{References}

[1]Ruan Yuhong, Wang Bo. Research of Comprehensive Method of Evaluating Teachers [J]. Social Sciences Journal of Colleges of Shanxi, 2005,17 (12) : 93-94

[2]Chen Shenbao. Research Based on Fuzzy Evaluation of Teaching Quality [J]. Mathematics in Practice and Theory, 2011,41 (6) : 72-78

[3]Liu Wei. Investigating the Comprehensive Method of Evaluating Teachers [J]. Journal OF Nanchang College, 2008,77 (4) : 116-118

[4]Li Lanyun, Yang Aimin, Li Xiao, etc. Multi - criteria Fuzzy Evaluation of Teaching Quality Based on Vague Aets[J]. Computer Engineering, 2011,37 (15） : 286-287,290

[5]Zhao Xiaoyan, Yu Wei. Analysis of the teacher evaluation based on improved TOPSIS method [J] Journal of Langfang Teacher's College (NATURAL SCIENCE EDITION), 2012,12 (2) : 60-63

[6]Zadeh L A. Fuzzy sets [J].Information and control, 1965 8(3):338-353

[7]Gao W L, Buehrer D J. Vague sets [J]. IEEE. Tran. Syst. Man. Cybern. 1993, 23(2):610-614

[8] Li Yanping, Liu Haihong, Dong Ronghui. Light Weight Scheme Selection for Car - body on Multi - objective Satisfaction [J]. Computer Integrated Manufacturing System, 2011,17 (1) : 37-44

[9] Zhang Shili, Zhang Yifei, Yuang Hangxin, etc. the Optimized model of Soft Ground Considering the Indicators' Uncertainty [J]. Journal of Railway Engineering, 2010, (3) : 19-23,48

[10] Zhang Wei. Optimization Design of the Main Structure of Tapered Roller Screen Transmission [J]. Coal Mine Machinery, 2009， 30 (3) ,15-17 